\title{
Clinical Application of SPECT-CT in Breast Cancer
}

\section{Abstract}

Radiopharmaceuticals used in standard nuclear medicine for patients with breast cancer are a well-known source of ionizing radiation, emitating gamma-photon particles: tumorotroponin cationic complexes such as ${ }^{99 \mathrm{~m}} \mathrm{Tc}$-Sestamibi/ Tetrofosmin (MIBI/TF); radiolabelled somatostatin analogues ${ }^{111} \mathrm{In}$-Ocrteoscan/ $/{ }^{99 \mathrm{~m}} \mathrm{Tc}-\mathrm{Tektrotyd}$;

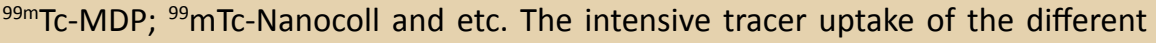
radiopharmaceuticals depends on the blood perfusion and their biodistribution, the proliferative activity of the tumor cells, the oxygen consumption, receptor status, and other factors of different tumors. For example the tumorotroponin cation complex ${ }^{99 \mathrm{~m}} \mathrm{Tc}-\mathrm{MIBI}$ concentrates in the mitochondria while ${ }^{99 \mathrm{~m}} \mathrm{Tc}-\mathrm{TF}$ uptake is also in the cytosol, due to the fact, that in active proliferative cells they are found in bigger quantity.

The introduction of the modern SPECT-CT camera to the clinical practice in the past 10 years dramatically improved the quality of the planer and SPECT images. The SPECT-CT camera is an integrated multimodal apparatus, containing CT scanner and SPECT $\gamma$-camera with a single bed for the patient, which makes it possible to obtain the CT scan.

SPECT scan and the combined or "fusion" SPECT-CT images. This new technology makes possible the visualisation of lesions with a size $<10 \mathrm{~mm}$, due to its higher separation ability of the detecting apparatuses, and the correction of dispersed $x$-rays through interactive methods.

Keywords: Breast cancer, Radiopharmaceuticals, SPECT-CT

\section{Sonya Sergieva ${ }^{1}$, Iglika Mihaylova ${ }^{2}$ Elena Alexandrova ${ }^{3}$, Albena Fakirova ${ }^{4}$ and Anna Saint-Georges ${ }^{5}$}

\section{Department of Nuclear Medicine, Sofia Cancer Center, Sofia, Bulgaria \\ 2 Department of Radiotherapy, National Oncological Hospital Plovdivsko Pole, Sofia, Bulgaria \\ 3 Department of Thoracic Surgery, National Oncological Hospital Plovdivsko Pole, Sofia, Bulgaria \\ 4 Department of Pathomorphology, Military Medical Academy, Georgy Sofiisky, Sofia, Bulgaria \\ 5 Deapartment of Radiology, Tokuda UH, Nikola Vaptzarov, Sofia, Bulgaria}

Corresponding author:

Sonya Sergieva

” sergieva.sonya@yahoo.com

Department of Nuclear Medicine, Sofia Cancer Center, Bulgaria

\section{Tel: +359 (2) 8752099}

Citation: Sergieva S, ihaylova I, Alexandrova E et al. Bellini Duct Carcinoma: Series of Two Clinical Cases Arch Cancer Res. 2015, 1: 1.

Received: November 18, 2015, Accepted: December 19, 2015, Published: December 27,2015

\section{SPECT Scan and the Combined or "Fusion" SPECT-CT Images}

This new technology makes possible the visualization of lesions with a size $<10 \mathrm{~mm}$, due to its higher separation ability of the detecting apparatuses, and the correction of dispersed x-rays through interactive methods [1-7].

The anatomical projections of the low dose (17-75 $\mathrm{mA}$ ) CT are used for the attenuation of the SPECT images and the precise topographic localization of the pathological lesions with an abnormal accumulation of radio pharmaceuticals. The diagnostic height dose CT images ( $>80 \mathrm{~mA}$ ) allows for the determination of the type of a morphological change of the visualized "hot" and "cold" lesions from the scintigraphy. This reflects on the reduced number of false-positive and false-negative results and therefore increasing the sensitivity and specificity of the scintigraphic studies. The nuclear medical part of the hybrid SPECT-CT images gives information for the functional activity of the primary neoplastic process of the breast and the secondary metastatic lesions, while the CT image is needed for determining the anatomical subtract of the visualized from the scintigraphy 
"hot" lesions. The SPECT-CT exams find a different clinical value in breast cancer [8-17].

\section{For the diagnosis of the primary tumor these exams have a limited role in the following cases}

1. For the determination of the exact localization of a primary lesion from an unclear image obtained with the other visualizing methods (dense breasts, implants), with the need to perform a target biopsy (Figure 1)

2. For the visualization of an occult primary tumor in patients with a metastatic process, and with clinical and laboratory data, pointing towards a breast origin

3. For visualizing multicentric and multifocal cancers (Figure 2).

SPECT-CT as a base line exam with ${ }^{99 \mathrm{~m}} \mathrm{Tc}-\mathrm{MIBI} / \mathrm{TF}$ in local advancing tumors with a lined up neoadjuvant chemotherapy, for the purpose of determining the volume of the neoplastic formation and the intensity of the accumulated of the applied radio marker. Very low values of SUV $(<2.2)$ of ${ }^{18}$ F-FDG have been noted in noninvasive and the mucinous histological variants of breast cancers, ductal carcinoma in situ, well differentiated lobular cancer, which are characterized by carbohydrate metabolism, similar to the one in normal cells $[18,19]$.

4. For the proper N/M staging of the disease in local advancing primary tumors of the breast and in inflammatory cancers (Figure 3).

\section{Preoperative $\mathrm{N}$ - staging of the disease}

The lymphoscintigraphic visualization of the sentinel lymph nodes (SLN) - detection and biopsy is a gold standard in the world's practice in the treatment of early stage breast cancers [2022]. In the last 5 years, intensively the purpose of the SPECT-CT examination has been researched along with the demonstration and the topography of the axillary SLN after a subcutaneous, intratumoral or a peri tumoral application of ${ }^{99 \mathrm{~m}} \mathrm{Tc}-\mathrm{Nanocoll}$, which is essential for their infra operative identification during the performance of a sentinel biopsy with a gamma probe $[23,24]$. This new technology improves the sensitivity of the conventional lymphoscintigraphy, which varieties between $72 \%$ and $94 \%$ up to $89 \%-100 \%$ due to the better resolution and contrast of the image [25,26], (Figures 4 and 5).

The identification of SLN sometimes leads to the establishment of atypical lymph drainage. In the literature we find data about parasternal lymph nodes which are seen in $20-25 \%$ of the patients after a peri tumoral injection of radio colloids; Intramammary in $6 \%$; Interpectoral - in $2 \%$; supraclavicular - in $3 \%$ of the cases $[25,26]$.

In accordance to the literature $[25,26]$ SPECT-CT exams increase the diagnostic sensitivity of the lymphoscintigraphic topogram in accordance to the visualization of:

- Additional "hot" SLN

- Visualization of ipsilateral parasternal lymph nodes

- SLN in cases of a negative planar lymphoscintigraphy

- Sub- and supraclavicular lymph nodes

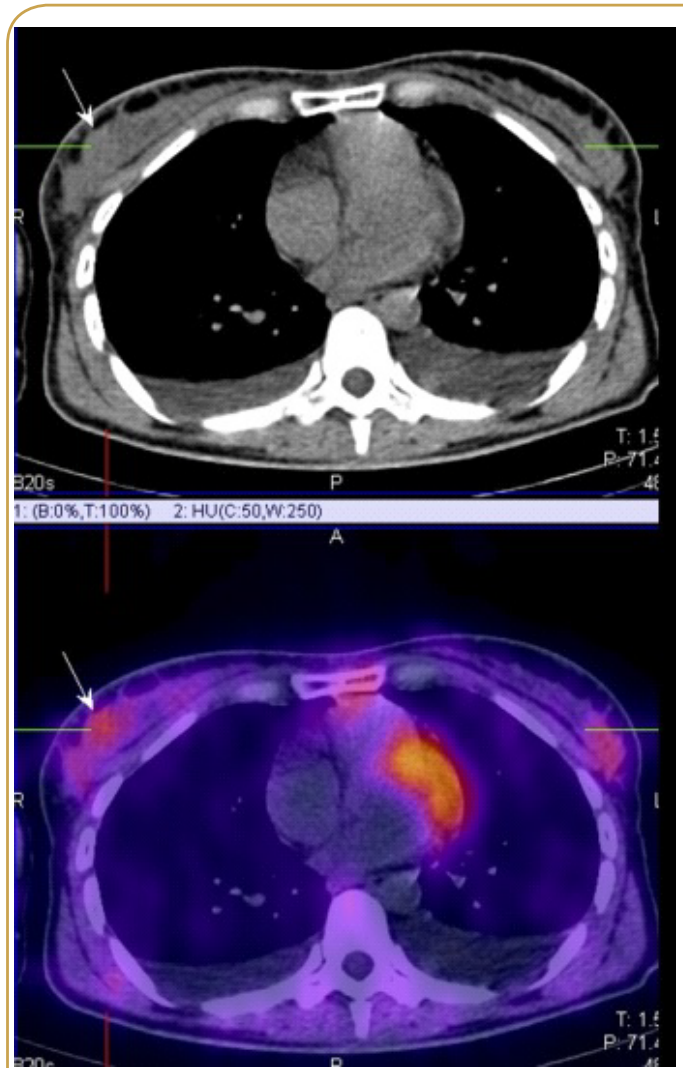

Figure 1 Patient with dense breasts. A high tracer uptake was showed in the SPECT-CT images in the central region of the right breast. After biopsy breast cancer was proved.
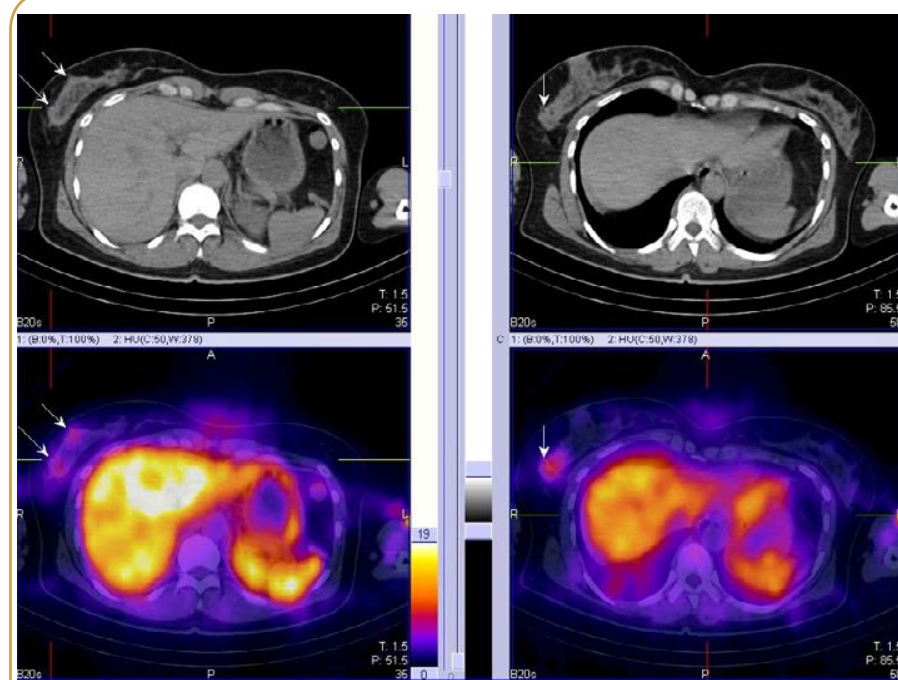

Figure 2 Patient with multicentric breast cancer on the right. SPECTCT showed 3 "hot" spots of high tracer uptake in the breast parenchyma.

- Prepectoral Intramammary SLN

- Interpectoral SLN

- Conjoining SLN on the planar image

- SLN in obese patients

- Increased in size, non palpable "cold" lymph nodes, located near SLN 

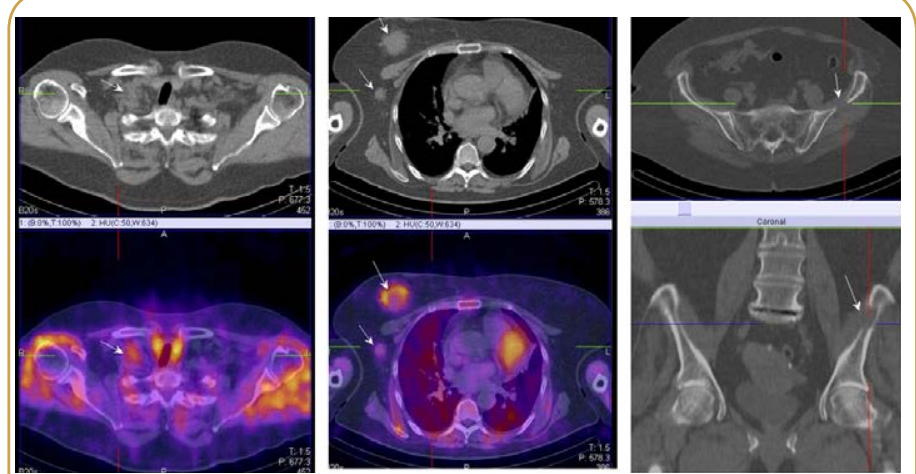

Figure 3

Patient with locally advanced cancer in the right breast. SPECTCT showed enlarged axillary and supraclavicular lymph nodes on the right and multiple osteolytic bone lesions with high tracer uptake.

Identification of parasternal SLN after a SPECT-CT has a clinical potential in medial and central localization of the primary tumors. The question about the intraoperative biopsy of these lymph nodes and the followed radiotherapy of this lymph pool is not yet resolved and it initiates different discussions.

The SPECT-CT studies can demonstrate exactly the intercostal space of the parasternal SLNs, which can be located and an intraoperative biopsy can be taken with an $\gamma$-detector or to get into the clinic tumoral volume in the radio therapeutic planning of high risk patients with central and medial localization. The identification of internal mammary SLNs is effected only in 75$80 \%$ of patients in a routine lymphoscintigraphy, in comparison to $\mathbf{> 9 0 \%}$ in axillary SLNs. $[25,26]$. One of the main reasons for this is the way of radio colloidal application. The visualization of axillary SLNs is obtained most often after a subdermal applicant above the tumor, with a volume of $0.2-0.3 \mathrm{ml}$, with an activity of 1-2 mCi. Scanning time is 45-90 min after injection. According to the literature, the visualization of internal mammary SLNs is done best after 2-4 deep parenchymal peri tumoral applications under ultrasound guidance, or after a single injection into the tumor with a volume of $0.3-0.5 \mathrm{ml}$, the detection is seen in 2-3 $\mathrm{h}$ after applying the radio colloid [23-25]. In a small percentage (2-3\%) of the patients with medial and central localizations a secondary infiltration but only into the parasternal lymph nodes is seen (Figure 5).

PET-CT examination is not recommended as a standard procedure for $\mathrm{N}$-staging of the axilla in early stage of breast cancer, due to the proven low sensitivity of the method, which is between $25 \%$ and $65 \%$ depending on the histological variant of the primary tumor and the respective lymphatic metastasis [27].

SPECT-CT with ${ }^{99 m}$ Tc-MIBI/TF is recommended in locally advanced tumors and inflammatory cancers, due to the existing high risk for the process to disseminate, with an involvement of all three levels of the axillary lymph pools as well as the ipsilateral parasternal lymph nodes in a medial and central localization of the primary tumor $[28,29]$.

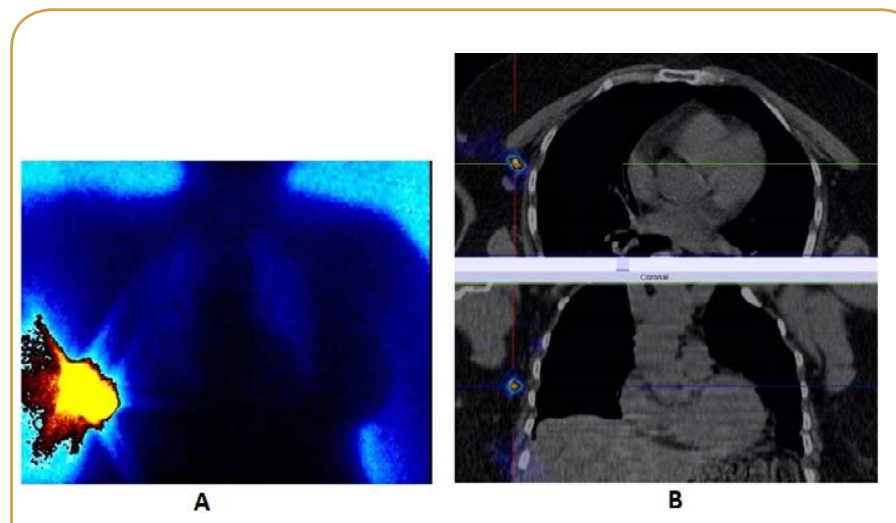

Figure 4 (A) Pt with carcinoma of the right breast. Planar lymphoscintigraphy was negative, (B) Late SPECT-CT images performed 3 h post injection showed 1 axillary SLN.

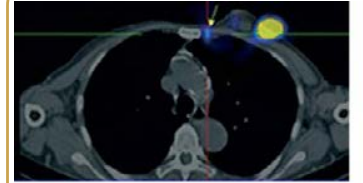

A

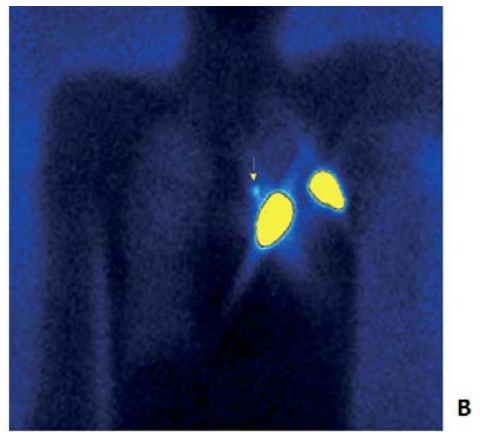

Figure 5 (A) Pt with carcinoma in the left breast. Planar image showed 1 parasternal SLN. (B) SPECT-CT images showed correct intercostal location of this internal SLN.

Multimodal SPECT-CT methods have the highest clinical purpose for re-staging and follow-up in patients with breast cancer after the completion of complex therapy

SPECT-CT with ${ }^{99 m}$ Tc-MIBI/TF is used for finding active proliferative tumor tissue with accompanied clinical and biochemical data for a local recurrence in the region of the remaining breast parenchyma, around a breast implant, or on the chest wall after an organ sparing surgery, bilateral subcutaneous mastectomy with an augmentation or after a radical mastectomy for the purpose of re-staging the diseases [29,30] (Figure 6).

For the diagnosis of a metastatic process and for determining it's level of dissemination with the presence of suspicions findings in a follow-up exam in patients with breast cancer. The module of choice for this purpose is the whole body bone scintigraphy followed by a target SPECT-CT exam in the zone of interest (Figure 7). The bone system is a predilection place for hematogeneous dissemination of this disease. The bone metastasis can be osteolytic, osteoblastic, or mixed [31,32].

PET-CT with ${ }^{18} \mathrm{~F}-\mathrm{FDG}$ is effective for visualizing the more aggressive osteolytic bone lesions and the intramedullar bone marrow lesions, while the osteosclerotic lesions are seen better on the bone scintigraphy after the application of ${ }^{99 \mathrm{~m} T c-M D P}$ 

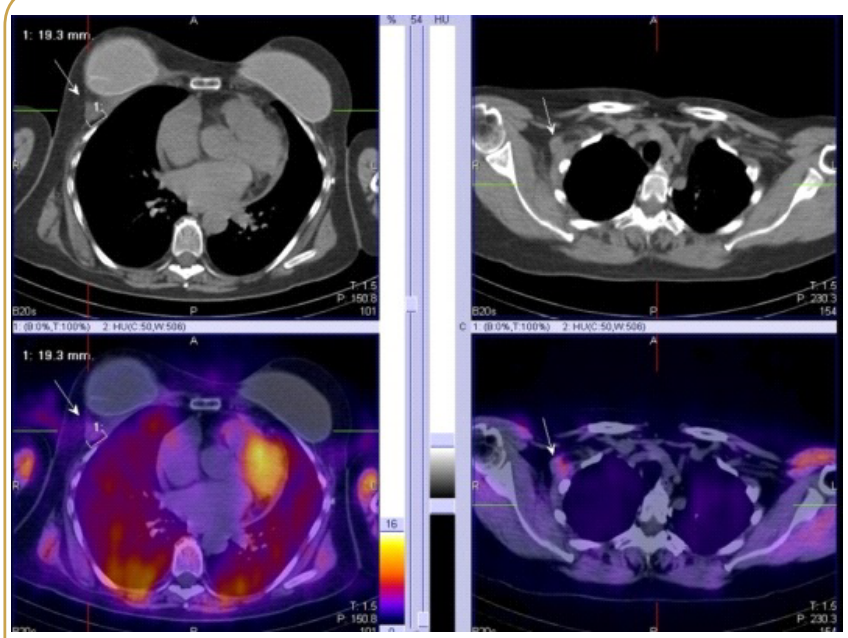

Figure 6 Pt with cancer in the right breast. Local recurrence on the right with supraclavicular lymphadenopathy after bilateral subcutaneous mastectomy and reconstruction of the breasts, chemotherapy and Ro-therapy CA15-3=212U/ml.

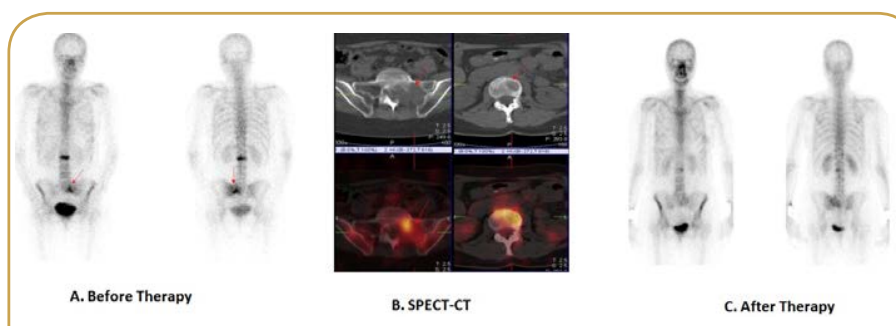

Figure 7 Patient with breast Ca after surgery. (A)Whole body bone scintigraphy showed abnormal tracer uptake in the $3^{\text {rd }}$ lumbar vertebra and distant sacroiliac joint on the left. (B) SPECT-CT images were positive for a large osteolytic metastatic lesion with soft-tissue component infiltrated the left sacrum and second osteolytic lesion in the $3^{\text {rd }}$ lumbar body. (C) External beam radiotherapy was performed. Control whole body bone scintigraphy showed decreased tracer uptake in these areas after treatment.

[33]. A higher sensitivity for the detection of tumor induced changes in the skeletal system is seen with the use of the new radio marker ${ }^{18} \mathrm{~F}$-Fluoride in comparison with ${ }^{18} \mathrm{~F}-\mathrm{FDG}$. After a radionuclide therapy with ${ }^{89}$ Srontium or ${ }^{153}$ Samarium, or therapy with a bisphosphonate component the osteolytic lesions consolidate with a formation of an osteosclerotic peripheral valve and are of mixed character.

In positive scintigraphic findings with ${ }^{99 \mathrm{~m} T c-M D P}$ of an uncertain character a SPECT-CT is performed to differentiate a potential benign diagnosis from a malignant process. Hybrid images are used localize a soft tissue component in some of the cases with direct bone and joint structural infiltration from a recurrence or metastatic formation, localized in the surrounding tissues (Figure 7). This is of great importance in the exact determination of the tumor volume in planning a stabilizing operative intervention or performing a palliative radiotherapy [31,32].

In general, the multimodal nuclear medical methods with ${ }^{99 \mathrm{~m}} \mathrm{Tc}$ $\mathrm{MIBI} / \mathrm{TF}$ can differentiate the active proliferating tumor tissue from post therapeutic fibrosis processes or physiological activity, therefore improving the diagnostic accuracy of the SPECT $[29,30]$ (Figure 8).

For determining the effect of the performed therapy from the compared analysis, of the studies obtained from the baseline exam and the follow-up SPET-CT exams during the therapeutic process and at the end of the complex treatment-a full therapeutic response, partial remission, stable disease, and progression (Figure 9). With the hybrid methods two indicators can be used - the morphological parameters determined from the CT projections - number of lesions, size, localization and the degree of the accumulation of radio pharmaceuticals in "hot" spots on the SPECT images $[29,30]$.

For imaging of breast cancer recurrence in tumors containing neuroendocrine component with radiolabelled somatostatin analogues ${ }^{111}$ In-Ocrteoscan or ${ }^{99 m} \mathrm{Tc}$-Tektrotyd with increasing level of chromogranin A (Figure 10).

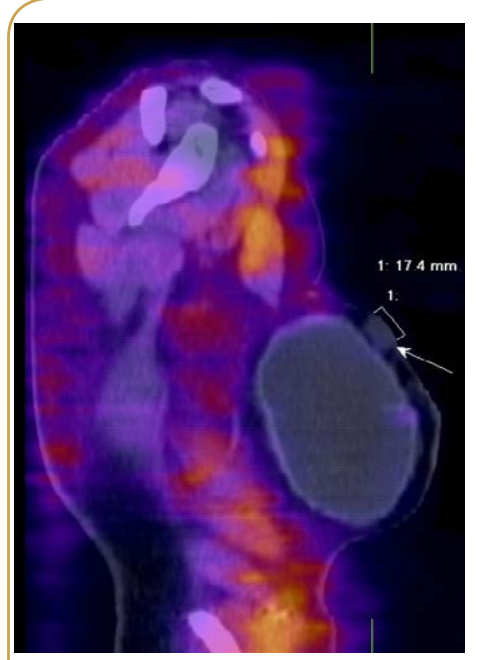

Figure 8 Patient with cancer in the right breast after bilateral subcutaneous mastectomy and reconstruction of the breasts, chemotherapy and Ro-therapy. There was a suspicious for local recurrence on the right above the implant. SPECT-CT was negative for ${ }^{99 \mathrm{~m} T C-M I B I}$ uptake in the soft tissue near the breast prosthesis, normal tissue was proved after biopsy.
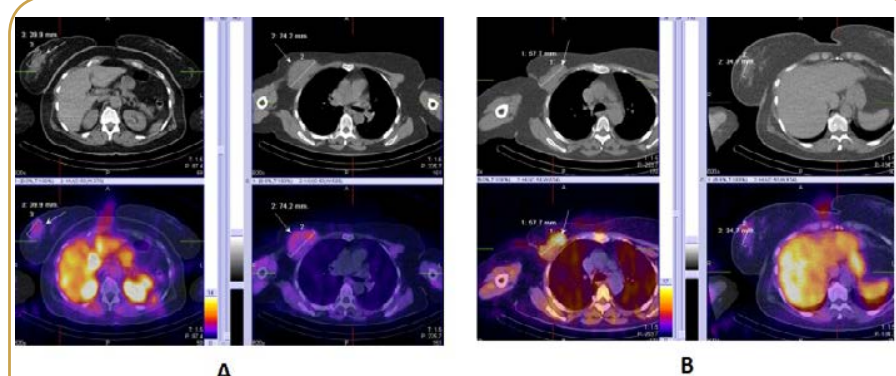

Figure 9 (A) Patient with recurrence in the right breast after quadrantectomy and axillary lymph node dissection. There was a suspicious for local recurrence on the right above the implant. SPECT-CT showed local recurrence in the breast and enlarged axillary lymph nodes on the right with intensive ${ }^{99 \mathrm{~m} T C-}$ $\mathrm{MIBI}$ uptake. (B) After complex chemo/hormonal therapy control SPECT-CT showed partial therapeutic response in the local breast recurrence and axillary lymph nodes with decreasing size and tracer uptake. 

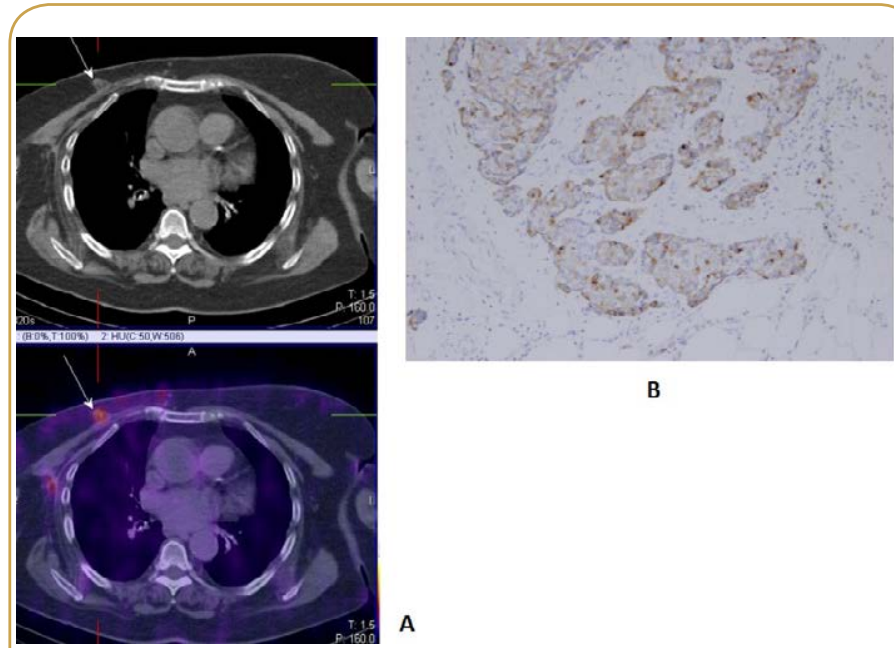

B

Figure 10 Patient with cancer in the right breast with neuroendocrine component after radical mastectomy and chemotherapy. $\mathrm{CgA}=170 \mathrm{ng} / \mathrm{ml}$. SPECT-CT showed intensive uptake of 99mTcTektrotyd - somatostatin analogues in the region of the operation on the right/A/. After surgery Immunohistochemistry was positive for CgA /B/ u Synaptophysin.

\section{Planning and radiotherapy}

SPECT-CT images have a practical use in determining the macroscopic (gross tumor volume-GTV) and the clinical (clinical tumor volume-CTV) targeted tumor volumes. Some patients demonstrate unsuspected tumor proliferative lesions, which increase the borders of the CT projection volumes, and in other cases reduction is needed in the predetermined borders, due to the differentiation of the fibrous tissue from the active metabolic tissue. This reflects on the priciest preparation of the individual radiotherapeutic plan in patients with breast cancer with the means of reducing the radio toxicity in a reached maximum therapeutic effect [32].

\section{Conclusion}

The introduction of multimodal SPECT-CT methods is used for diagnosis, staging, and fallow-up for patients with breast cancer increased the diagnostic specificity and sensitivity of the nuclear medical diagnosis, which is of an important clinical value in determining and planning individual therapeutic approach in patients with breast cancer. 


\section{References}

1 Wang HC, Chen DR, Kao CH, Lin CC, Lee CC (2002) Detecting breast cancer in mammographically dense breasts: comparing technetium$99 \mathrm{~m}$ tetrofosmin mammoscintigraphy and ultrasonography. Cancer Invest 20: 932-938.

2 Madeddu G, Spanu A (2004) Use of tomographic nuclear medicine procedures, SPECT and pinhole SPECT, with cationic lipophilic radiotracers for evaluation of axillary lymph node status in breast cancer patients. Eur J Nucl Med Imaging 31: S23-S34.

3 Schillaci O, Buscombe JR (2004) Breast scintigraphy today: indications and limitations. Eur J Nucl Med Mol Imaging 31 Suppl 1: S35-45.

4 Liberman M, Sampalis F, Mulder DS, Sampalis JS (2003) Breast cancer diagnosis by scintimammography: a meta-analysis and review of the literature. Breast Cancer Res Treat 80: 115-126.

5 Taillefer $\mathrm{R}$ (2005) Clinical applications of 99mTc-sestamibi scintimammography. Semin Nucl Med 35: 100-115.

6 Luini A, Gatti G, Ballardini B, Zurrida S, Galimberti V, et al. (2005) Development of axillary surgery in breast cancer. Ann Oncol 16: 259262.

7 Sergieva S, Alexandrova E, Baichev G, Ganchev G, Tzonevska A, et al. (2002) Lymphoscintigraphy and immunohistochemistry for the assessment of sentinel lymph nodes in patients with breast cancer. Hell J Nucl Med 2: 127-129.

8 Schillaci O, Buscombe JR (2004) Breast scintigraphy today: indications and limitations. Eur J Nucl Med Mol Imaging 31 Suppl 1: S35-45.

9 Madeddu G, Spanu A (2004) Use of tomographic nuclear medicine procedures, SPECT and pinhole SPECT, with cationic lipophilic radiotracers for evaluation of axillary lymph node status in breast cancer patients. Eur L Nucl Med Imaging 31: S23-S34.

10 Spanu A, Farris A, Schillaci O, Chessa F, Solinas ME, et al. (2003) The usefulness of $99 \mathrm{mTc}$ tetrofosmin scintigraphy in patients with breast cancer recurrences. Nucl Med Commun 24: 145-154.

11 Beyer T, Freudenberg LS, Townsend DW, Czernin J (2011) The future of hybrid imaging-part 1: hybrid imaging technologies and SPECT/CT. Insights Imaging 2: 161-169.

12 Schäfers KP, Stegger L (2008) Combined imaging of molecular function and morphology with PET/CT and SPECT/CT: image fusion and motion correction. Basic Res Cardiol 103: 191-199.

13 Núñez R, Erwin WD, Wendt RE 3rd, Stachowiak A, Mar M, et al. (2010) Acquisition parameters for oncologic imaging with a new SPECT/multislice CT scanner. Mol Imaging Biol 12: 110-138.

14 Schillaci O, Danieli R, Filippi L, Romano P, Cossu E, et al. (2007) Scintimammography with a hybrid SPECT/CT imaging system. Anticancer Res 27: 557-562.

15 Schillaci $O$ (2005) Is there a clinical role for scintimammography in breast cancer diagnosis? J Nucl Med 46: 1571-1573.

16 Goldsmith SJ, Parsons W, Guiberteau MJ, Stern LH, Lanzkowsky L, et al. (2010) SNM practice guideline for breast scintigraphy with breastspecific gamma-cameras 1.0. J Nucl Med Technol 38: 219-224.

17 Schillaci O, Danieli R, Manni C, Simonetti G (2004) Is SPECT/CT with a hybrid camera useful to improve scintigraphic imaging interpretation? Nucl Med Commun 25: 705-710.

18 Escalona S, Blasco JA, Reza MM, Andradas E, Gómez N (2010) A systematic review of FDG-PET in breast cancer. Med Oncol 27: 114129.

19 Radan L, Ben-Haim S, Bar-Shalom R, Guralnik L, Israel O (2006) The role of FDG-PET/CT in suspected recurrence of breast cancer. Cancer 107: 2545-2551.

20 Veronesi U, Paganelli G, Viale G, Luini A, Zurrida S, et al. (2003) A randomized comparison of sentinel-node biopsy with routine axillary dissection in breast cancer. N Engl J Med 349: 546-553.

21 Naik AM, Fey J, Gemignani M, Heerdt A, Montgomery L, et al. (2004) The risk of axillary relapse after sentinel lymph node biopsy for breast cancer is comparable with that of axillary lymph node dissection: a follow-up study of 4008 procedures. Ann Surg 240: 462-468.

22 Luini A, Gatti G, Ballardini B, Zurrida S, Galimberti V, et al. (2005) Development of axillary surgery in breast cancer. Ann Oncol 16: 259262.

23 Cheng G, Kurita S, Torigian DA, Alavi A (2011) Current status of sentinel lymph-node biopsy in patients with breast cancer. Eur J Nucl Med Mol Imaging 38: 562-575.

24 van der Ploeg IM, Nieweg OE, Kroon BB, Rutgers EJ, Baas-Vrancken Peeters MJ, et al. (2009) The yield of SPECT/CT for anatomical lymphatic mapping in patients with breast cancer. Eur J Nucl Med Mol Imaging 36: 903-909.

25 Mariani G, Bruselli L, Kuwert T, Kim EE, Flotats A, et al. (2010) A review on the clinical uses of SPECT/CT. Eur J Nucl Med Mol Imaging 37: 1959-1985.

26 van der Ploeg IM, Valdés Olmos RA, Kroon BB, Nieweg OE (2008) The Hybrid SPECT/CT as an additional lymphatic mapping tool in patients with breast cancer. World J Surg 32: 1930-1934.

27 Helwick C (2010) PET scans not recommended for most patients with breast cancer: potential new controversy in breast cancer testing. American health and drug benefits. NCCN Meeting Highlights 3: 2-4.

28 Spanu A, Chessa F, Sanna D, Cottu P, Manca A, et al. (2009) Scintimammography with a high resolution dedicated breast camera in comparison with SPECT/CT in primary breast cancer detection. Q J Nucl Med Mol Imaging 53: 271-280.

29 Sergieva S, Alexandrova E, Baichev G, Parvanova V (2012) SPECT-CT in breast cancer. Arch Oncol 20: 45-54.

30 Sergieva S, Mihaylova I, Alexandrova E, Dimcheva M, Mansi L (2015) SPECT-CT in Radiotherapy Planning, with Main Reference to Patients with Breast Cancer. Curr Radiopharm 8: 9-18.

31 Fogelman I, Blake GM, Cook GJ (2013) The isotope bone scan: we can do better. Eur J Nucl Med Mol Imaging 40: 1139-1140.

32 Sergieva S, Alexandrova E, Robev B, Mihaylova I, Dimcheva M (2015) Bone SPECT-CT in diagnosis and staging of osseous metastases. PJNM 5: 1-8.

33 Koolen BB, Vegt E, Rutgers EJ, Vogel WV, Stokkel MP, et al. (2012) FDG-avid sclerotic bone metastases in breast cancer patients: a PET/ CT case series. Ann Nucl Med 26: 86-91. 